\title{
Something lost - something gained: the ASCI begins its second century
}

\author{
Charles L. Sawyers
}

Howard Hughes Medical Institute, Human Oncology and Pathogenesis Program, Memorial Sloan-Kettering Cancer Center, New York, New York, USA.

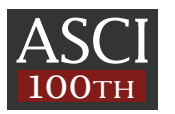

For the hundredth anniversary of the American Society for Clinical Investigation, we have invited various members of the community to recount here the impact that the Society, its annual meeting, and The Journal of Clinical Investigation have had on them. Their recollections provide a view of the changes that have occurred in academic medicine in general and for the physician-scientist in particular.

The year 2008 marks the hundredth anniversary of the founding of the American Society for Clinical Investigation (ASCI) on May 11, 1908, at the Willard Hotel in Washington, DC. The ASCI began as a rebellion of sorts against the Association of American Physicians (AAP) by a handful of young clinicians who felt that a different organization was required to place greater emphasis on medical science over clinical practice. To mark this historic event, we have solicited vignettes from recent generations of ASCI members (including one father-son pair) who reflect on the organization and its impact on their careers. Their stories reveal a remarkable shift in the culture of our physician-scientist profession over the past several decades.

Before commenting on these reflections, it is worth noting that the first president of ASCI, Samuel Meltzer, was not one of the Young Turks but rather their mentor. Born in Russia, Meltzer was trained in Germany, then established a thriving clinical practice in Harlem, New York. His passion, however, lay in medical science, and in 1904, at age 53, he closed his practice to become director of Physiology and Pharmacology at the newly established Rockefeller Institute for Medical Research. Four years later, he delivered the first ASCI presidential address, entitled "The Science of Clinical Medicine: What It Ought to Be and the Men to Uphold It," in which he challenged his younger colleagues to obtain proper training in science but warned them not to lose sight of the medical focus of their investigations. Meltzer argued, “... who should be the men to carry on the research in this field, what should be their qualifications? In the first place, they must have a training fitting them to carry out investigations in conformity with the requirements existing in all pure sciences. They must not only be informed and trained in the other sciences of medicine, but must have carried on various investigations in one or more of these pure sciences, so as to become familiar with careful scientific methods and imbued with a scientific spirit. However, after all these preparations they must select clinical research as the main field of their scientific activity. Clinical science will not thrive through chance investigations by friendly neighbors from the adjoining practical and scientific domains." Thus, the ASCI was founded on the principles of "meritorious, original investigation in the clinical or allied sciences of medicine" (direct quote from the criteria for admission to ASCI in the 1908 charter), and Meltzer himself served as ASCI's first role model of mentorship (1).

As we fast-forward to the more recent ASCI history reported in the vignettes that follow, we learn of nostalgia for the annual

Conflict of interest: The author has declared that no conflict of interest exists. Citation for this article: J. Clin. Invest. 118:1213-1214 (2008). doi:10.1172/JCI35463. meeting of the ASCI, the AAP, and the AFMR (American Federation for Medical Research, a group of younger physicians formed after the ASCI) held in Atlantic City (the AFMR was previously known as the American Federation for Clinical Research [AFCR], as mentioned in several of the following articles). This meeting, at that time, represented the most visible forum for presentation of new data, highlighted by the much-coveted slots in the plenary session. The camaraderie, the excitement of new discovery across disciplines, and the social interaction of junior and senior investigators, as well as trainees, ring loud in the articles (and photographs) that follow. But the meeting of the organizations - also known as the Tri-Societies meeting - has adapted over the years, replaced by specialty society meetings that now serve as the principal venue for scientific exchange. To preserve its relevance, the ASCI and AAP adopted the current joint meeting format, now centered in Chicago, in which the agenda consists of a series of thematically linked, longer talks delivered by luminaries rather than trainees. It is clear that many lament the loss of the Atlantic City spirit.

Despite coming of age in the specialist generation, I vividly recall the joy of learning of my election to ASCI in 1999, the first validation of my work outside of my own small cocoon. However, I must confess the skepticism I felt that day about the relevance of a general physician-scientist society meeting. Many say we are now a purely honorific society, but is there no greater purpose to our annual gathering each spring? Clearly I am not alone in my doubts, because even the decision to accept a leadership position in our organization today is met with ambivalence, as 2007 ASCI president Barbara Weber revealed in her presidential address: she initially declined to run for the ASCI's presidential vacancy in deference to "feeding the beast" of ever-growing administrative duties (that is, until Craig Thompson, an indomitable ASCI member, paid her a visit) (2).

Having now served on the ASCI Council for three years, a tenure culminating in this year's term as president, I can assure you that feeding this particular beast is entirely worth the time and effort. As hard as it has been to carve time away from my own busy world of cancer biology and experimental therapeutics, I have not regretted a single moment. Just as the Young Turks of 1908 so clearly recognized, these three years have taught me that we still share common scientific goals and have much to learn much from each other. Let me illustrate.

Each February, the ASCI Council gathers to review the pool of nominations to membership, select the recipients of the Young Investigator Award, and choose the Stanley J. Korsmeyer Award winner. Despite our packed two-day schedule, this year I convinced my colleagues to arrive a bit earlier than usual in order to add a 
new scientific session to our meeting. What followed was a series of informal, spirited talks on topics ranging from viral hepatitis to developmental cardiac anomalies, skeletal muscular dystrophies, and cancer therapeutics. This exercise sparked our recognition of the diversity of talent among us as well as the remarkable scientific overlap in our respective fields. As just one example, the signal transduction pathway abnormalities associated with cardiac outflow tract defects are similarly involved in cancer initiation and progression. Not only do many of us study the same sets of genes, we assemble complementary sets of scientific reagents that can enhance each other's work. You can imagine the dinner conversations that followed.

Yes, the Atlantic City days are over, and specialty meetings will continue to be the venue for reporting late-breaking discoveries. But I am convinced that the ASCI remains an important venue for scientific exchange and for insuring that the lessons we learn in career development, mentoring, and juggling administrative duties are communicated to subsequent generations. Just as Samuel Meltzer instructed the first Young Turks in 1908, we continue to listen to our senior ASCI colleagues - for example, to the sug- gestion by Lefkowitz (3) that we add short presentations of latebreaking science and to Kelley's recommendation (4) that we pass along our collective wisdom (to our junior colleagues in the American Physician Scientists Association [APSA] who now join us each year). Last, we all share the unique responsibility of ensuring that our discoveries have an impact in medical practice. In this greatest of all challenges, we will always remain relevant, united, and the closest of colleagues.

Address correspondence to: Charles L. Sawyers, Howard Hughes Medical Institute and Memorial Sloan-Kettering Cancer Center, 1275 York Avenue, New York, New York, USA 10021. Phone: (646) 888-2138; Fax: (646) 888-2595; E-mail: sawyersc@mskcc.org.

1. Brainard, E.R. 1959. History of the American Society for Clinical Investigation, 1909-1959. J. Clin. Invest. 38:1784-1864.

2. Weber, B.L. 2007. In the palace of the sultan: 2007 American Society for Clinical Investigation Presidential Address. J. Clin. Invest. 117:1727-1731.

3. Lefkowitz, R.J. 2008. The annual ASCI meeting: does nostalgia have a future? J. Clin. Invest. 118:1231-1233.

4. Kelley, W.N. 2008. ASCI: reflections on the first 100 years and a proposal for the next. J. Clin. Invest. 118:1217-1219.

\title{
The ASCl, the spring meetings, and growing up in academic medicine: a personal perspective
}

\author{
Anthony S. Fauci \\ National Institute of Allergy and Infectious Diseases, NIH, Bethesda, Maryland, USA.
}

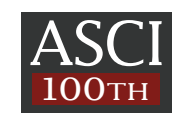

For many young physician-scientists, the American Society for Clinical Investigation spring meetings are the backdrop to their initiation into academic medicine. Membership in the ASCI is a high honor and represents one's maturation and accomplishment in clinical research. The ASCI continues to provide this meeting forum for young investigators who aspire to emulate their idols and mentors just as I did in 1969 when I attended the spring meetings in Atlantic City for the first time.

It seems both like yesterday and forever ago that in spring 1969 scores of my fellow clinical associates and I, MDs from across the country who were taking clinical research fellowships at the NIH immediately following residencies in internal medicine, piled into our cars and headed north. We left Bethesda, Maryland, drove around the Beltway and up Route 95 to Atlantic City for our first experience at the "clinical meetings." We went because we were told that we had to go by our bosses (Sheldon Wolff, in my case), since it was at the ritual of the annual spring meetings where academic medicine and clinical research showed its stuff. The same scene was repeated at virtually every academic medical center throughout the country. Young, aspiring physician-scientists came to see, hear, and learn from the masters, the very individuals whose papers they had read and quoted on rounds during their house staff training. None of us from the NIH group had been in the laboratory long enough to have accumulated enough data to present; most were still in the clinical year of a three-year fellowship and

Conflict of interest: The author has declared that no conflict of interest exists. Citation for this article: J. Clin. Invest. 118:1214-1217 (2008). doi:10.1172/JCI34724. had not even entered the laboratory. Nonetheless, this trip marked the beginning of an extraordinary journey in which the American Society for Clinical Investigation and its annual spring meetings, usually held jointly with the Association of American Physicians (AAP) and the American Federation for Clinical Research (AFCR), became the backdrop to our initiation and ultimate maturation in academic medicine. There are so many aspects of the uniqueness and importance of the ASCI and its annual meeting that come to mind; I would like to briefly recall some of them.

\section{The ASCl: the gold standard of excellence}

It became clear to me as I progressed over the years through my fellowship, and as I began assuming independence as a basic and clinical investigator, that the ASCI represented the gold standard of excellence in medical research. There was no question that you submitted and hopefully presented your very best work to the assembled ASCI members at the annual meetings; if you were lucky, you might even get to present at a plenary session. One of the most exciting moments in my early career was presenting a paper in 1973 at the AFCR plenary session on my year-long work 